\title{
PSICOPATOLOGÍA DESCRIPTIVA E HISTORIA DE LA PSIQUIATRÍA
}

\author{
Rafael Huertas
}

Dpto. Historia de la Ciencia, CEH, CSIC.

\author{
Germán E. Berrios y Filiberto Fuentenebro, Delirio. Historia, Clínica, Metateoría, \\ Madrid, Editorial Trotta, 1996, $230 \mathrm{pp}$.
}

Pocas veces se tiene la oportunidad de asistir al ilusionado comienzo de proyectos editoriales que, en tiempos como los actuales -de crisis de ideas y de pensamiento único-, suponen un evidente riesgo, tan solo compensado por la decisión y el empuje de un editor independiente cuya opción no es exclusivamente el mercado, sino la calidad de lo publicado, con independencia de que los temas abordados por los autores se circunscriban a un ámbito intelectual o científico más bien reducido.

La editorial Trotta acaba de abrir, dentro de su Colección Estructuras y Procesos, una Serie cuyo título genérico es Pensamiento, Psicopatología y Psiquiatría. Serie que, a juzgar por su primer título, permite abrigar muy fundadas esperanzas sobre su continuidad y sobre la calidad de una línea editorial que puede tener, pese a su especialización, un público fiel e interesado.

Delirio. Historia, Clínica, Metateoría, es un libro de utilidad innegable para psiquiatras y psicólogos, pero también para historiadores de la Ciencia en sentido amplio y, de manera particular, de la Medicina y de la Psiquiatría. Un libro, a mi juicio, modélico tanto por su metodología, como por sus propios contenidos, por razones que expondré a continuación.

En primer lugar, porque pone a disposición del lector español un concienzudo trabajo realizado desde los presupuestos teóricos y metodológicos de la Escuela de Cambridge, cuyas aportaciones - a través de monografías diversas y, sobre todo, de un órgano de expresión como History of Psychiatry-, han supuesto una innegable novedad en la historiografía psiquiátrica de los últimos tiempos.

Ahora podemos disponer de una obra publicada originariamente en castellano, gracias al esfuerzo editorial de Trotta y al trabajo de Germán Berrios y Filiberto Fuentenebro, este último, sin duda, el más sólido introductor y difusor en España de esa historia conceptual de los síntomas y, en definitiva, de la historia de la psicopatología descriptiva que el mencionado grupo de Cambridge propugna. Una parcela de la Historia de la Psiquiatría que viene a completar, de manera muy cabal, otros enfoques de la misma, como la Historia Social, la institucional, etc., de mucho más arraigo en nuestro país.

En segundo lugar, centrándome, brevemente, en la utilidad que el libro tiene desde el punto de vista de la Historia de la Ciencia, recordaré que, de manera tradicional, se suele indicar que dicha disciplina juega tres papeles fundamentales en la formación del científico: un papel epistemológico (que intenta explicar la racionalidad interna del discurso científico), un papel contextualizador (que 
considera y analiza cómo la ciencia se ha desarrollado en distintos contextos históricos, geográficos, culturales, sociales, etc.), y un papel crítico (de crítica positiva o negativa según los casos).

En mi opinión, Delirio cumple con creces estos tres papeles, estas tres funciones. Por un lado, cumple una función epistemológica, porque partiendo de un análisis genealógico exhaustivo del delirio como síntoma psicopatológico, desde lo que los autores llaman su protohistoria (las aportaciones de médicos y filósofos de los siglos XVII y XVIII), hasta su historia propiamente dicha (su desarrollo conceptual a lo largo del XIX y del XX), se llega a algo sobre lo que yo no insistiré aquí -otros colegas lo harán probablemente desde otros foros- pero que me parece capital: el análisis del concepto de delirio en la actualidad y, dando todavía un paso más, la formulación por parte de los autores de su propia teoría. Puede verse muy claramente cómo la Historia se convierte en una herramienta epistemológica de primer orden, no solo para comprender el presente, sino incluso para avanzar en la elaboración, quien sabe si de futuros paradigmas.

Por otro lado, contextualiza perfectamente la evolución del concepto de delirio por autores, por países y por épocas, lo cual resulta enormemente útil por su claridad y por su ordenación. No cabe duda que la psicopatología descriptiva se desarrolló primeramente en la Francia de la primera mitad del siglo XIX. Pinel, Esquirol, Falret, Georget, pero también Moreau de Tours, Lasègue, el belga Guislain, etc., comenzaron a elaborar el lenguaje necesario y a sentar las bases del descriptivismo en psicopatología, pero no es menos cierto que dicha psicopatología descriptiva fue desarrollándose y difundiéndose en otros lugares por autores alemanes e ingleses, fundamentalmente, que Berrios y Fuentenebro no olvidan.

Merece la pena destacar cómo, ya en el siglo XX, empiezan a aparecer, tímidamente y casi como un espejismo, psiquiatras españoles como Llopis, Valenciano, Martín Santos o Castilla del Pino, que son rescatados y revisados por los autores del libro.

Contextualización histórica y geográfica, pero también contextualización socio-política y profesional. Es evidente que este esfuerzo descriptivo del que estamos hablando no responde solo al desarrollo interno del saber psicopatológico sino que responde a otros factores que inciden directamente en el mismo: la influencia de la mentalidad anatomoclínica, puesta a punto por la escuela de París -por el grupo de la Charité- sobre el alienismo; la necesidad de diagnosticar y de hacer historias clínicas homologables, si se me permite la expresión, son elementos a tener en cuenta. Pero no lo son menos aspectos corporativos, de tipo profesional e institucional que el libro recoge con acierto, como el proceso de profesionalización del alienismo francés a partir de la famosa Ley de 1838, y, en este marco, los debates en el seno de la Société médico-psychologique y las aportaciones publicadas en los Annales médico-psychologiques.

Por último, la Historia de la Ciencia debe tener una función crítica, si bien ésta puede entenderse de varias maneras. Por un lado, puede considerarse una función de crítica positiva el panegírico que, tradicionalmente, ha consistido en elevar la dignidad de la profesión y de los profesionales, mediante más o menos completas genealogías de ilustres varones que han servido, y sirven, para apoyar o justificar intelectualmente y, desde luego, falazmente, a los que hoy ostentan el poder —el poder psiquiátrico- y dominan la disciplina desde la Academia o desde otros ámbitos.

Función crítica es también la que desempeñaron a finales de los años sesenta y en la década de los setenta, sociólogos e historiadores radicales y psiquiatras comprometidos con la realidad asistencial. Trabajos sobre el manicomio y sobre el tratamiento moral a veces muy iconoclastas, pero que supusieron un innegable revulsivo para toda una corriente historiográfica que, una vez despojada de excesos y de especulaciones, sigue teniendo su interés en el panorama global.

El libro que nos ocupa, desarrolla, sin embargo, su crítica de una manera diferente - diferente y novedosa-. Crítica en la que yo establecería además dos planos de concreción: en primer lugar, 


\section{ENSAYOS}

en un plano, más histórico, se analizan las aportaciones concretas de los distintos autores, lo que permite, lejos de toda especulación, lejos de todo torcido interés ideológico, explicar quién es quién en la historia del delirio. La desmitificación de Jaspers sería, en este sentido, un buen ejemplo de lo que quiero decir. La puntualización de que fue Baillarger y no Jaspers el que describió la "percepción delirante", tiene un gran interés; pero sobre todo, la contraposición de las concepciones psicopatológicas del autor alemán con las de los grandes semiólogos franceses de entresiglos. El discurso filosófico y escasamente clínico de Jaspers versus el virtuosismo clínico de Séglas o la solidez y madurez nosológica de Chaslin, basada en la experiencia clínica. La reivindicación de esta semiología, poco conocida y con frecuencia eclipsada por la enorme difusión que tuvo la obra de Jaspers, es, sin duda, otro de los grandes logros de Berrios y Fuentenebro. Creo que no estará de más decir que las páginas dedicadas a este tema saben a poco y, desde luego, auguran lo que probablemente será un futuro trabajo, más amplio, más monográfico, sobre cómo de la mera descripción de los síntomas se va pasando a una verdadera semiología, esto es, a un auténtico sistema cognitivo.

En segundo lugar, este libro posee también un trasfondo crítico que es preciso destacar y que tiene que ver con los propios problemas, tanto teóricos como prácticos, de la psiquiatría actual. La existencia de una pseudo-psicopatología farmacológica, el evidente reduccionismo que supone el DSM (elevado a la categoría de fetiche), etc..., han ido, poco a poco, degradando la psicopatología descriptiva. Estoy de acuerdo con Fuentenebro cuando afirma, a todo el que quiera escucharle, que existe un verdadero "malestar en la cultura psicopatológica", cuando se lamenta del frágil andamiaje conceptual que en la actualidad tiene buena parte de la práctica psiquiátrica actual y de las escasas perspectivas teóricas que pueden ofrecerse a aquellos que pretenden formarse en medicina mental.

Su respuesta no se ha hecho esperar, Delirio. Historia, clínica, metateoría, es también un ejemplo impecable de como se hace Historia en el Presente y para el Presente. Este Presente que nos está tocando vivir, a psiquiatras y psicólogos - jóvenes y seniores-, a historiadores y filósofos - jóvenes y seniores -, para los que esta obra deberá constituir, a partir de ahora, punto de referencia ineludible para todos aquellos interesados en abordar, de manera honesta, la historia, la clínica, la metateoría de los trastornos mentales. 